Kapustynskaia O A. Coronary heart disease among adult population evacuated from the 30-km zone of the Chernobyl NPP (Descriptive epidemiologic research results). Observation period 1988-2012. Pedagogy and Psychology of Sport. 2015;1(2)53-65. eISSN 2450-6605. DOI http://dx.doi.org/10.5281/zenodo.15081

http://apcz.umk.pl/czasopisma/index.php/PPS/article/view/12224

Original text

Kapustynskaia $\mathrm{O}$ A. Coronary heart disease among adult population evacuated from the 30-km zone of the Chernobyl NPP (Descriptive epidemiologic research results). Observation period 1988-2012. Journal of Education, Health and Sport. 2015;5(2):53-65. ISSN 2391-8306. DOI: $10.5281 /$ zenodo.15081

http://ojs.ukw.edu.pl/index.php/johs/article/view/2015\%3B5\%282\%29\%3A53-65

https://pbn.nauka.gov.pl/works/535830

http://dx.doi.org/10.5281/zenodo.15081

\begin{tabular}{llllllllllll}
\hline Formerly Journal of & Health & Sciences. & ISSN & $1429-9623$ & $/$ & $2300-665 X$ & Archives & 2011 & - & 2014
\end{tabular} http://journal.rsw.edu.pl/index.php/JHS/issue/archive

Deklaracja.

Specyfika i zawartoséc merytoryczna czasopisma nie ulega zmianie.

Zgodnie z informacją MNiSW z dnia 2 czerwca 2014 r., że w roku 2014 nie będzie przeprowadzana ocena czasopism naukowych; czasopismo o zmienionym tytule otrzymuje tyle samo punktów co na wykazie czasopism

The journal has had 5 points in Ministry of Science and Higher Education of Poland parametric evaluation. Part B item 1089. (31.12.2014)

This article is published with open access at Licensee Open Journal Systems of Kazimierz Wielki University in Bydgoszcz, Poland and Radom University in Radom, Poland

This article is distributed under the terms of the Creative Commons Attribution Noncommercial License which permits any noncommercial use, distribution, and reproduction in any medium,

provided the original author(s) and source are credited. This is an open access article licensed under the terms of the Creative Commons Attribution Non Commercial License
(http://creativecommons.org//icenses/by-nc/3.0/) which permits unrestricted, non commercial use, distribution and reproduction in any medium, provided the work is properly cited.

Creative Commons Attribution Non Commercial License (http://creativecommons.org/licenses/by-nc/3.0/) which permits unrestricted, non commercial

use, distribution and reproduction in any medium, provided the work is properly cited.

Received: 20.10.2014. Revised 18.01.2015. Accepted: 25.01.2015.

УДК 616-036.22

ИШЕМИЧЕСКАЯ БОЛЕЗНЬ СЕРДЦА У ВЗРОСЛОГО НАСЕЛЕНИЯ, ЭВАКУИРОВАННОГО ИЗ ЗО-КМ ЗОНЫ ЧЕРНОБЫЛЬСКОЙ АЭС

(РЕЗУЛЬТАТЫ ДЕСКРИПТИВНЫХ ЭПИДЕМИОЛОГИЧЕСКИХ ИССЛЕДОВАНИЙ). ПЕРИОД НАБЛЮДЕНИЯ 1988-2012 ГОДЫ

\title{
CORONARY HEART DISEASE AMONG ADULT POPULATION EVACUATED FROM THE 30-KM ZONE OF THE CHERNOBYL NPP (DESCRIPTIVE EPIDEMIOLOGIC RESEARCH RESULTS). OBSERVATION PERIOD 1988-2012
}

\author{
О.А. КАПУСТИНСКАЯ \\ OA KAPUSTYNSKAIA
}

\begin{abstract}
ГУ «Национальный научный центр радиационной медицины НАМН Украины» SI "National Scientific Center of Radiation Medicine of National Academy Medical Science of Ukraine", Kiev
\end{abstract}

\section{Резюме}

Определение и анализ динамики уровня заболеваемости взрослого эвакуированного населения на ИБС, включая и отдельные ее формы, с учетом возраста на момент аварии, пола и времени с момента аварии. В статье использованы данные Государственного реестра Украины лиц, пострадавших вследствие Чернобыльской катастрофы (ГРУ) и статистические данные Минздрава Украины о заболеваемости взрослого населения Украины. Исследования проводились в целом по заболеваемости на ИБС, а также по нозологическим формам: стенокардия; инфаркт миокарда; хроническая ИБС. Дескриптивное эпидемиологическое исследование проведено за период 19882010 годы. Когорта взрослого эвакуированного населения составила 55022 человека, из них 22056 мужчин и 32966 женщин. Для сравнения использованы статистические данные о заболеваемости взрослого населения Украины. В работе использован также метод внутреннего сравнения, позволяющий оценить достоверность отличий показателей заболеваемости по периодам наблюдения. Анализ проведен по следующим п’яти периодам (1988-1992 гг., 1993-1997 гг., 1998-2002 гг., 2003-2008 гг., 2009-2010 гг.).

За результатами 24 летнего медицинского наблюдения установлено, что заболеваемость на ИБС взрослого эвакуированного населения имеет существенные возрастные, половые и временные отличия. Повышение уровня заболеваемости на ИБС независимо от возраста на момент аварии следует отнести на период 12 - 22 года. Пик заболеваемости у лиц, возраст которых на момент аварии составил 40-60 лет, отмечен в третьем периоде наблюдения, т.е. спустя 12-16 лет с момента аварии на ЧАЭС, у лиц, эвакуированных в возрасте 18-39 лет - спустя 17-22 года и сохраняется на таком же уровне в последнем периоде. Спустя 24 года после аварии заболеваемость эвакуированных в возрасте 18-39 лет превышает показатели первого периода в 4 раза, а второго периода - в 3 раза. В возрастной группе 40-60 лет в последний период наблюдения отмечается тенденция снижения. Обращает внимание достаточно высокий уровень заболеваемости на ИБС лиц, возраст которых на момент аварии составил 40-60 лет в первые шесть лет с момента аварии, что, очевидно обусловлено влиянием трех основных факторов: «возраст», «скрининг-эффект» и «психо-социальный стресс». У лиц, эвакуированных в возрасте 18-39 лет, не установлено достоверной разницы в уровне заболеваемости мужчин и женщин, в то время, как у женщин 40-60 лет показатели заболеваемости на ИБС выше по сравнению с мужчинами, за исключением последнего этапа наблюдения. В отношении отдельных форм ИБС можно отметить превалирование хронической ИБС. У лиц, эвакуированных в возрасте 18-39 лет, отмечен более высокий темп роста частоты стенокардии и инфаркта миокарда в сравнении с возрастной группой 40-60 лет. В 2009-2010 гг. уровень заболеваемости этими болезнями у лиц, эвакуированных в возрасте 40-60 лет, почти сравнялся с заболеваемостью начальных этапов наблюдения. Высказано предположение о возможной связи роста частоты ИБС в исследуемом контингенте пострадавших с радиационным облучением и влиянием комплекса факторов нерадиационной природы, связанных и не связанных с последствиями аварии на ЧАЭС, что является задачей дальнейших аналитических эпидемиологических исследований.

Ключевые слова: авария на ЧАЭС, взрослое эвакуированное население, заболеваемость, ишемическая болезнь сердца 


\begin{abstract}
The determination and analyses of the dynamics of the evacuated adults sickness rate of the coronary heart disease also including its particular types including of age at the time of the accident sex and from the moment of the accident. The materials of the Ukrainian public register of people who suffered from the Chernobyl accident (UPR) and the statistical data of the Ministry of Healthcare about the sickness of the Ukrainian population are used in the article. Subject of inquiry: adult population at the time of the accident avacuated from the 30-km Zone of the Chernobyl APP. Object of research - Coronary heart disease. The research was made on the coronary heart disease in whole and also due to nosological forms: angina pectoris; cardiac infarction; chronic coronary heart disease. Descriptive epidemiologic research was made for the period of $1988-2010$ years. The cohort of adult avacuated population constituted 55022 people, 22056 men and 32966 women off them. For the comparison the statistic data about the sickness of adult population of Ukraine were used. In the article was also used the method of inner comparison, which allows to evaluate the credibility of the sickness rate figures difference for the periods of observation. The analisys is carried through following five periods (1988-1992 years, 1993-1997 years, 1998-2002 years, 2003-2008 years, 2009-2010 years).

In accordance with the 24-years medical observation was determined that the coronary heart disease incidence of the adult evacuated population has significant differences due to age, sex and time. The increase in the coronary heart disease incidence regardless age at the moment of the accident is to be considered for the period of 12-22 years. The peak of the sickness for those, who were 40-60 at the time of the accident, was registered for the third period of observation, i. e. after 12-16 years from the moment of the accident at the Chernobyl NPP, for those, evacuated at the age of 18-39 - after 17-22 years and remains at the same level in the last period. 24 years later after the accident the rate of sickness of those, evacuated at the age 18-39, surpasses the figures of the first period four times and the second period - 3 times. In the age group of $40-60$ years in the last period of observation the decrease is noted. High enough coronary heart disease incidence of those people, whose age at the time of accident was 40-60 at the first six years from the moment of the accident keeps attention, that, obviously, was caused by the influence of three main factors: "age", "screening-effect" and "psycho-social stress". For people evacuated at the age of 18-39 the proved difference in the sickness rate of men and women wasn't stated, whereas the figures of coronary heart disease for women of 40-60 years old are higher in comparison with men with an exception of the last stage of observation. What the particular forms of the coronary heart disease concerns the prevaluating of the cronical coronary heart disease is noted. For the people evacuated at the age of 18-39, was noted the higher frequency growth rate of angina pectoris and cardiac infarction in comparison to the people of age 40-60. In 2009-2010 the sickness rate for these diseases for the people evacuated at the age of 40-60 was almost equal to the sickness rate of the first stages of observation. There is the hypothesis about the possible connection between frequency growth rate of coronary heart disease for the contingent of the sufferers with the exposure to radiation among those under observation and the impact of the complex of factors of nonradiation nature connected and not connected to the consequences of the Chernobyl APP accident, which is the task for the further analitical epidemiologic research.
\end{abstract}

\title{
Key words: Chernobyl APP accident, adult avacuated population, sickness rate, coronary heart disease
}

\section{Введение}

Распространенность ишемической болезни сердца (ИБС) приобрела размеры эпидемии во второй половине XX века. По результатам оценки 10-летнего риска развития фатальных сердечно-сосудистых заболеваний (CC3) в европейской популяции Украина относится к странам наиболее высокого риска. 62\% больных, страдающих от ИБС, расценивают качество своей жизни как «неудовлетворительное» или «плохое» [1].

Результаты долгосрочных эпидемиологических исследований показали, что послеаварийный период ознаменовался значительным ростом у пострадавших широкого спектра неопухолевых заболеваний [2]. В структуре наиболее высокие уровни неопухолевых заболеваний отмечаются по классу заболеваний системы кровообращения [3]. В частности, рост уровня заболеваемости ИБС у участников ликвидации аварии установлен в период 1998-2002 годов, т.е. спустя 12-17 лет с момента аварии. Аналогичная ситуация установлена и в отношении взрослого на момент аварии эвакуированного населения $[4,5]$. В структуре заболеваний, как у участников ликвидации, так и эвакуированных, первые места занимают болезни системы кровообращения, органов пищеварения и дыхания. Особое внимание заслуживает высокий удельный вес заболеваемости ишемической болезнью сердца (ИБС) [6]. Однако и до настоящего времени проблема неопухолевой заболеваемости контингентов, пострадавших вследствие аварии на ЧАЭС, в т.ч. и на ИБС еще недостаточна исследована и решена. 
Важными является выяснение роли таких факторов, как возраст на момент аварии, пол, время с момента аварии, а также изучение и оценка влияния радиационного и нерадиационных факторов риска развития этого заболевания.

Настоящее сообщение посвящено результатам дескриптивного анализа динамики и структуры заболеваемости ИБС взрослого на момент эвакуации населения с учетом возраста на момент аварии, пола и времени после аварии. Период анализа составил 1988-2010 гг., т.е. 24 года.

\section{Цель исследования}

Определение и анализ динамики уровня заболеваемости взрослого эвакуированного населения ИБС, включая и отдельные ее формы с учетом возраста на момент аварии, пола и времени с момента аварии.

\section{Объем и методы исследования}

В статье использованы данные Государственного реестра Украины лиц, пострадавших вследствие Чернобыльской катастрофы (ГРУ) и официальные статистические отчетности Минздрава Украины о заболеваемости взрослого населения Украины, которые ведутся с 1993 года.

Объект исследования: взрослое на момент аварии население, эвакуированное из 30км зоны ЧАЭС. Предмет исследования - ИБС.

На протяжении исследуемого периода использовались две классификации болезней МКБ-9: код ИБС 410.0-414.9 (до 2002 года) и МКБ-10: код I20.0-I25.9 (в последующие годы).

Исследования проводились в целом по заболеваемости ИБС, а также по нозологическим формам:

стенокардия ( код 413.0-413.9 по МКБ-9 и код I20.0-I20.9 по МКБ-10);

инфаркт миокарда (код 410.0-412.0 по МКБ-9 и код I21.0-I22.9 по МКБ-10);

хроническая ИБС (код 413.0-414.9 по МКБ-9 и код I25.0-I25.9 по МКБ-10).

Дескриптивное эпидемиологическое исследование проведено за период 1988-2010 годы (таблица 1).

Таблица 1. Количественное распределения когорты взрослого эвакуированного населения по возрасту на момент аварии на ЧАЭС

\begin{tabular}{|l|c|c|c|}
\hline $\begin{array}{l}\text { Когорта эвакуированного населения } \\
\text { с учетом возраста на момент } \\
\text { аварии, лет }\end{array}$ & $\begin{array}{c}\text { абсолютное } \\
\text { количество } \\
\text { лиц }\end{array}$ & в т.ч. мужчин & в т.ч. женщин \\
\hline Вся когорта в возрасте 18-60 лет & 55022 & 22056 & 32966 \\
\hline Субкогорта возрастом 18-39 лет & 30779 & 13036 & 17743 \\
\hline Субкогорта возрастом 40-60 лет & 24243 & 9020 & 15223 \\
\hline
\end{tabular}


За данными ГРУ в период 1988-2010 гг. ежегодно осматривалось от 20 до 32 тыс. человек.

Было выделено две возрастные группы (18 - 39 лет и 40 -60 лет на момент аварии).

Уровень заболеваемости на указанные болезни оценивали путем расчета коэффициента $I D$ по формуле:

количество новых случав заболеваний за данный период времени $\cdot 1000$ $I D=$

Число наблюдений ( чел. - лет)

95\% доверительный інтервал( СI) определяли по формуле:

$C I=I D \pm 1,96 \sqrt{I D / Y}$,

где $Y$ - численность популяции (чел. лет).

Для оценки уровня достоверности отличий данных рассчитывали ошибку средней по формуле:

$$
\pm m=\sqrt{\frac{R \times q}{n}}, \quad \text { где }
$$

$\boldsymbol{R}$ - показатель заболеваемости, рассчитанный на 1000 человек;

$\boldsymbol{q}$ - соответственно (1000 - R),

$\boldsymbol{n}$ - число обследованных (чел. лет).

Достоверность отличий результатов оценивалось также путем расчета критерия $\mathrm{t}$ Ст'юдента.

В качестве группы сравнения использованы статистические данные о заболеваемости взрослого населения Украины. В работе использован также метод внутреннего сравнения, позволяющий оценить достоверность отличий показателей заболеваемости в послеаварийный период (по сравнению с периодом 1988-1992 гг. и 1993 1997 гг).

Проанализированы уровень и структура заболеваемости ИБС взрослого эвакуированного населения. Уровень общей заболеваемости ИБС и отдельных ее форм определяли по периодам наблюдения с учетом пола и возраста.

\section{Результаты исследования}

В течение послеаварийного периода изменения показателей заболеваемости ИБС происходили в определенной последовательности.

Как свидетельствуют данные (рис.1) динамика заболеваемости эвакуированных ИБС имеет существенные возрастные и временные отличия. 


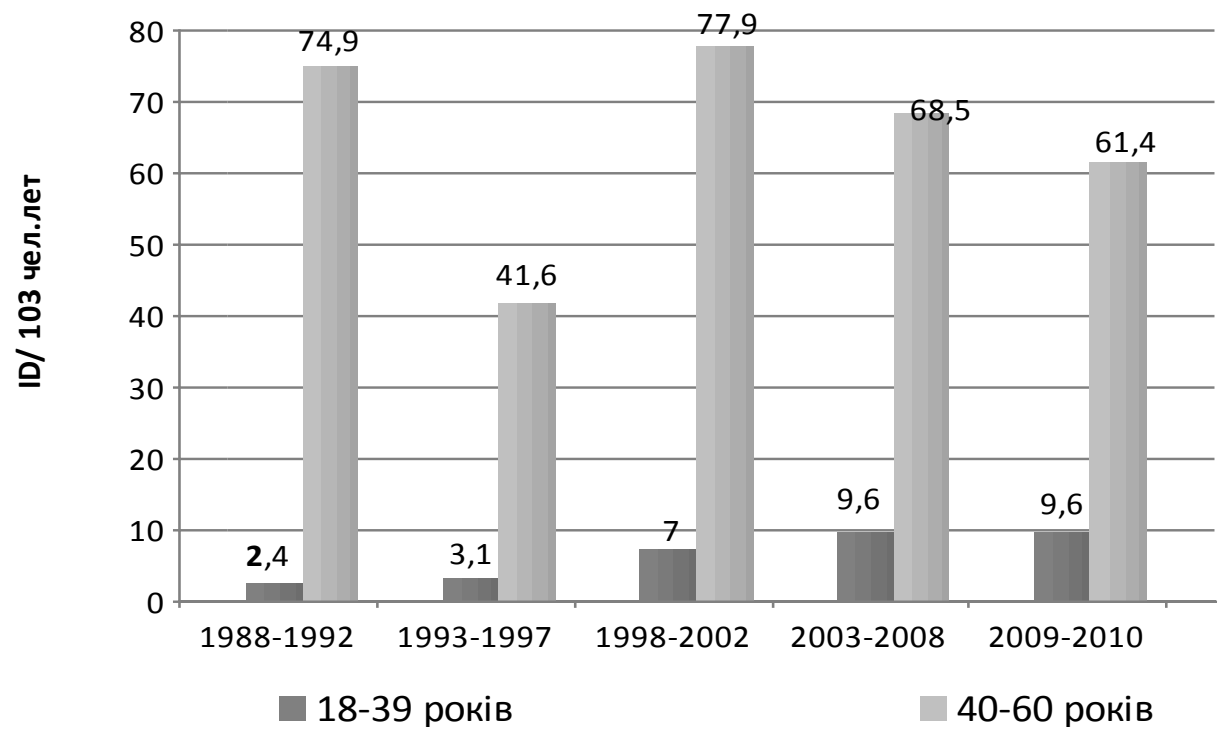

Рисунок 1. Динамика уровня заболеваемости ИБС взрослого эвакуированного населения по периодам наблюдения с учетом возраста на момент аварии (ID / $10^{3}$ чел.-лет

У лиц, возраст которых на момент аварии составлял 18-39 лет отмечается постепенное увеличение уровня заболеваемости. Особенно высокий уровень установлен в третьем, четвертом и пятом периодах, т.е. через 12-24 года после аварии.

У лиц, возраст которых на момент аварии составил 40-60 лет повышение уровня заболеваемости ИБС следует также отнести на период 12-24 года после аварии, с пиком заболеваемости в третьем периоде ( 12-17 лет после аварии).

Следует отметить, что уровень заболеваемости лиц старшего возраста, т.е. 40-60 лет на момент аварии, превышает уровень, установленный для младшей возрастной группы (1839 лет), что мы связываем, прежде всего, с влиянием фактора «возраст».

Обращает внимание достаточно высокий уровень заболеваемости ИБС лиц, возраст которых на момент аварии составил 40-60 лет, в первые 6 лет после аварии. Очевидно, что в данном случае сказалось существенное влияние основных факторов: «возраст», «скринингэффект» и «психо-социальный стресс».

Данные о динамике уровня заболеваемости взрослого эвакуированного населения ИБС в зависимости от пола и возраста представлены на рис. 2. 


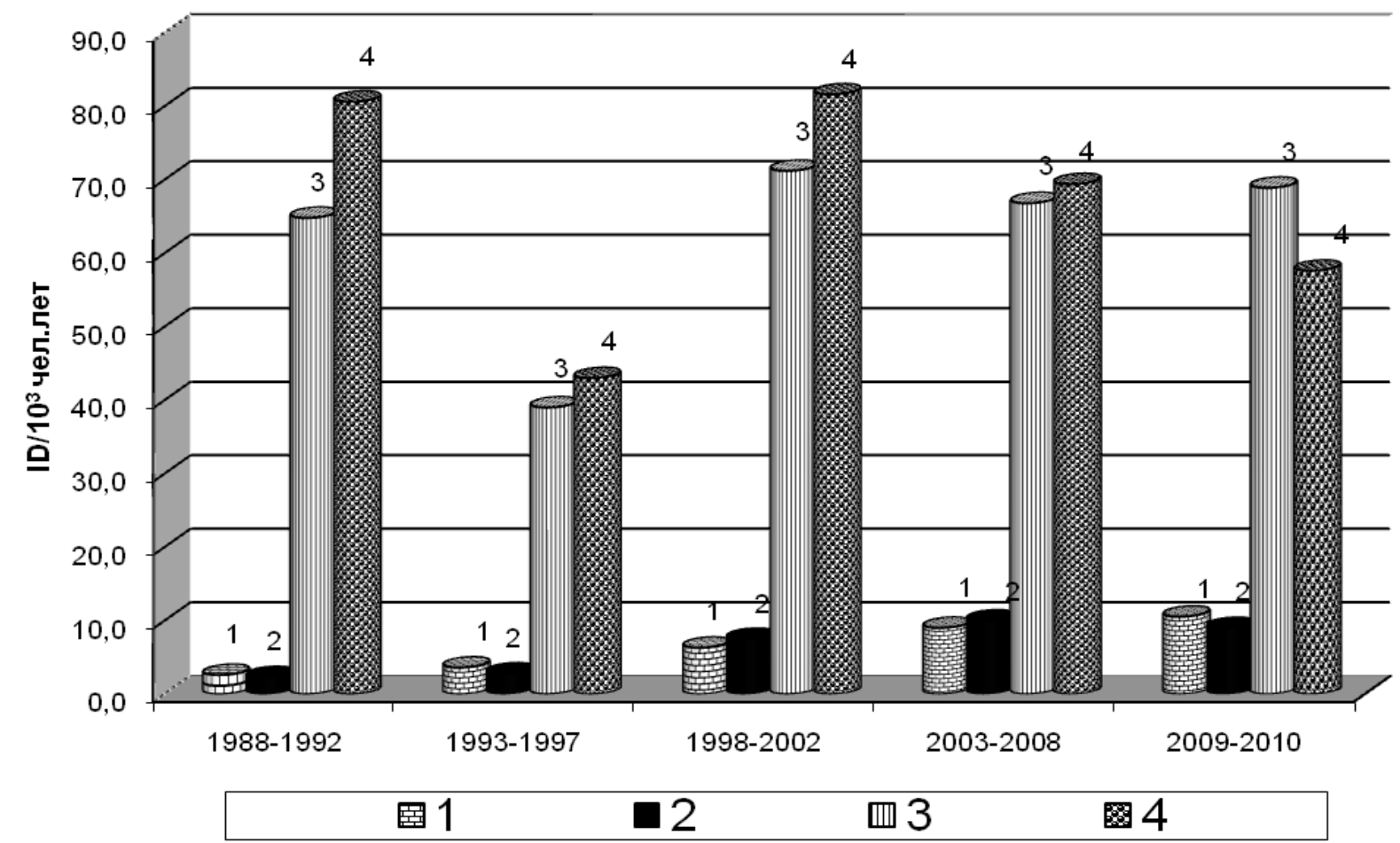

1 - заболеваемость мужчин в возрасте

3 - заболеваемость мужчин в возрасте 18-39 лет ИБС

2 - заболеваемость женщин в возрасте 18-39 лет ИБС

40-60 лет ИБС

4 - заболеваемость женщин в возрасте 40-60 лет

Рисунок 2. Динамика уровня заболеваемости ИБС взрослого эвакуированного населения по периодам наблюдения в зависимости от пола и возраста (ID / $10^{3}$ чел.-лет)

Как видно из рисунка у лиц, возраст которых на момент аварии составлял 18-39 лет, не установлено достоверной разницы в заболеваемости мужчин и женщин, в то время, как у женщин 40-60 лет показатели заболеваемости ИБС выше по сравнению с мужчинами, кроме последнего этапа наблюдения.

Обращает внимание следующее: у лиц, возраст которых на момент аварии 18-39 лет, существенных половых отличий в уровне заболеваемости ИБС не установлено. Как у мужчин, так и женщин отмечается постепенный рост частоты заболеваемости, особенно начиная с третьего периода.

В отношении эвакуированных в возрасте 40-60 лет на момент аварии, то следует отметить, что наиболее высокий уровень заболеваемости ИБС отмечается у женщин, за исключением последнего периода. Также очевидно, что в первом периоде не исключается влияние выше указанных факторов.

Дальнейший анализ заболеваемости по периодам наблюдения у исследуемых лиц проводился по отдельным нозологическим формам (ИБС, инфаркт миокарда, стенокардия), рис. 3 и рис. 4. 


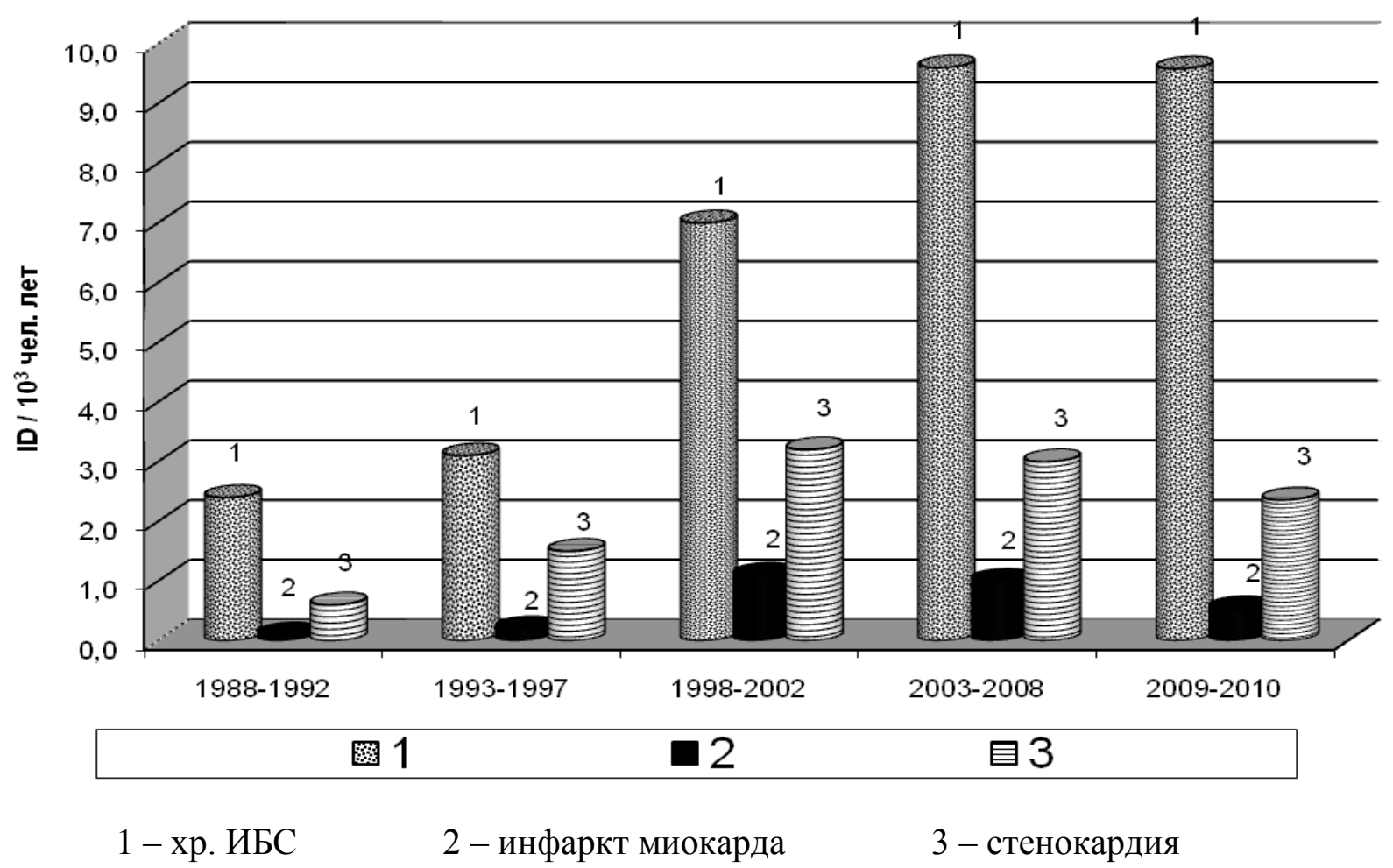

Рисунок 3. Динамика уровня заболеваемости отдельных форм ИБС в когорте эвакуированного населения в возрасте 18-39 лет по периодам наблюдения (ID / $10^{3}$ чел.-лет)

С рисунка 3 видно, что в целом заболеваемость ИБС у лиц данной возрастной группы постепенно возрастает и особенно с третьего периода.

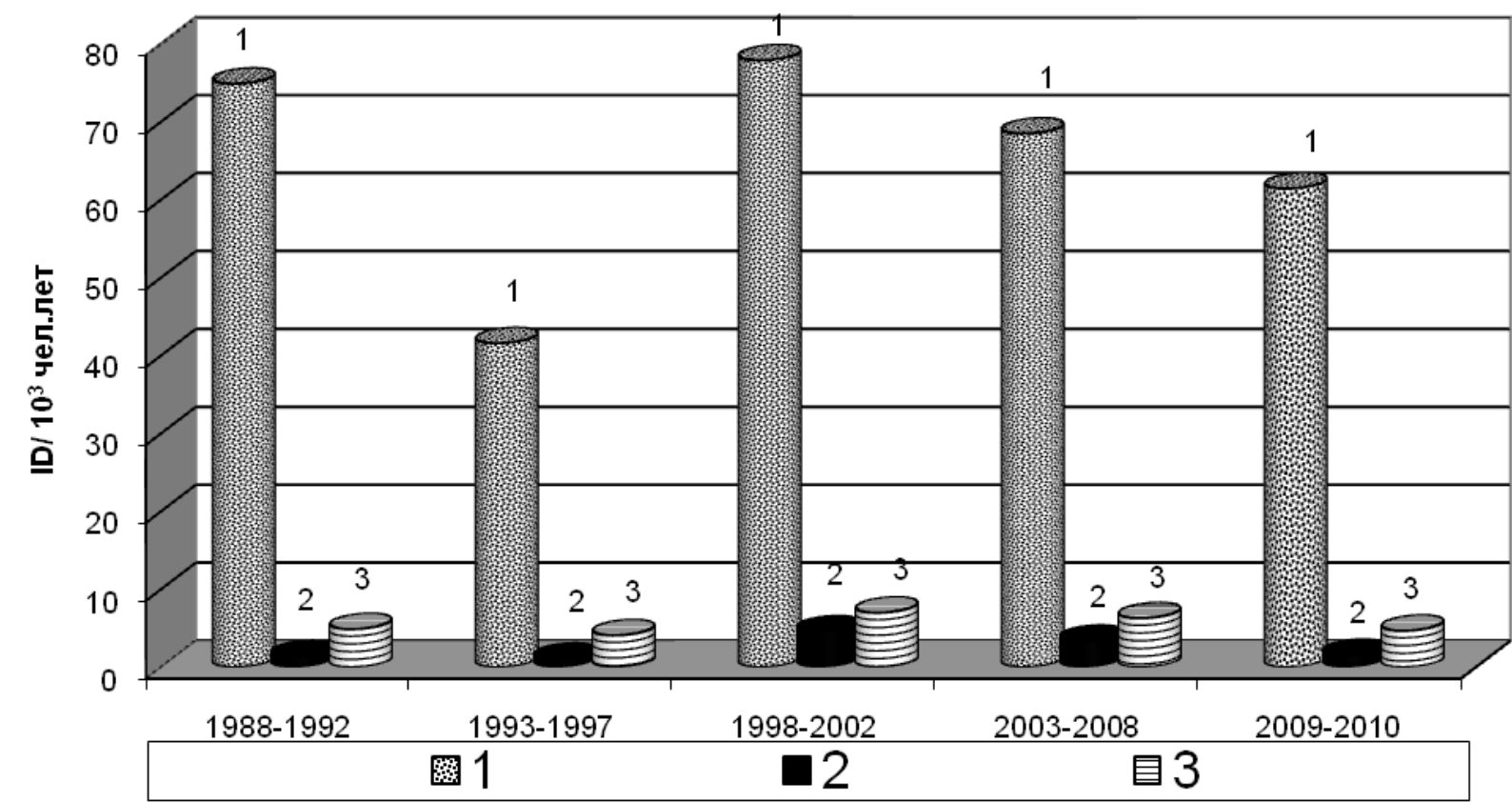

$$
1 \text { - хр. ИБС } 2 \text {-инфаркт миокарда } 3 \text {-стенокардия }
$$

Рисунок 4. Динамика уровня заболеваемости на отдельные формы ИБС в когорте взрослого эвакуированного населения в возрасте 40-60 лет по периодам наблюдения (ID / $10^{3}$ чел.-лет) 
Как свидетельствуют данные рис. 3 и рис. 4 среди нозологических форм доминирует хроническая ИБС (95\%). Общую группу ИБС также формируют стенокардия и острый инфаркт миокарда.

По результатам исследования установлено, что у лиц в возрасте 18-39 лет отмечается постепенное повышение показателей заболеваемости хронической ИБС в течение второгочетвертого периодов наблюдения с максимальным уровнем в 2003-2008 годах со стабилизацией в 2009-2010гг.

У лиц 40-60 лет не прослеживается такой четкой динамики. Показатели второго этапа (1993-1997 гг.) значительно ниже первого периода, в третьем периоде зафиксировано максимальное повышение заболеваемости с последующим снижением в периоде 2009-2010 Гг.

Что касается половых различий, то картина выглядит следующим образом (таблицы 2 и 3$)$.

Таблица 2. Уровень заболеваемости на нозологические формы ИБС в когорте эвакуированного населения в возрасте 18-39 лет по пятилетним периодам наблюдения в зависимости от пола (ID / $10^{3}$ чел.-лет )

\begin{tabular}{|c|c|c|c|c|c|c|}
\hline \multirow{2}{*}{$\begin{array}{c}\text { Нозологические формы } \\
\text { заболеваний }\end{array}$} & \multirow[t]{2}{*}{ Пол } & \multicolumn{5}{|c|}{ Периоды наблюдения } \\
\hline & & 1988-1992 & 1993-1997 & 1998-2002 & $2003-2008$ & $2009-2010$ \\
\hline \multirow{2}{*}{$\begin{array}{l}\text { - острый инфаркт } \\
\text { миокарда }\end{array}$} & $\bar{M}$ & $0,2 \pm 0,09$ & $0,4 \pm 0,1$ & $1,3 \pm 0,2^{*}$ & $1,2 \pm 0,2$ & $0,79 \pm 0,25^{*}$ \\
\hline & Ж & $0,09 \pm 0,05$ & $0,1 \pm 0,05$ & $0,9 \pm 0,1 *$ & $0,9 \pm 0,1$ & $0,39 \pm 0,14 *, * *$ \\
\hline \multirow[t]{2}{*}{ - стенокардия } & $\mathrm{M}$ & $0,7 \pm 0,2$ & $2,5 \pm 0,3$ & $3,4 \pm 0,2 * 9 *$ & $2,9 \pm 0,3$ & $1,82 \pm 0,38^{*}$, \\
\hline & Ж & $0,4 \pm 0,1$ & $0,8 \pm 0,1$ & $3,0 \pm 0,2$ & $3,0 \pm 0,2$ & $* * 2,69 \pm 0,36 *$ \\
\hline \multirow[t]{2}{*}{ - хроническая ИБС } & $\mathrm{M}$ & $2,6 \pm 0,3$ & $3,6 \pm 0,4$ & $6,3 \pm 0,4^{*}$ & $9,0 \pm 0,5^{*}$ & $7,92 \pm 0,79 *$ \\
\hline & Ж & $2,3 \pm 0,2$ & $2,8 \pm 0,3$ & $7,5 \pm 0,4^{*}$ & $10,0 \pm 0,4^{*}$ & $5,91 \pm 0,54 *, * *$ \\
\hline
\end{tabular}

Примечание. * - достоверная разница между величинами первого пятилетнего периода наблюдения и последнего;

** - достоверная разница между величинами второго пятилетнего периода наблюдения и последнего.

Таблица 3. Уровень заболеваемости на нозологические формы ИБС в когорте эвакуированного населения в возрасте 40-60 лет по пятилетним периодам наблюдения в зависимости от пола (ID / $10^{3}$ чел.-лет )

\begin{tabular}{|c|c|c|c|c|c|c|}
\hline \multirow{2}{*}{$\begin{array}{c}\text { Нозологические } \\
\text { формы заболеваний }\end{array}$} & \multirow[t]{2}{*}{ Пол } & \multicolumn{5}{|c|}{ Периоды наблюденияй } \\
\hline & & 1988-1992 & 1993-1997 & $1998-2002$ & 2003-2008 & $2009-2010$ \\
\hline \multirow{2}{*}{$\begin{array}{l}\text { - острый инфаркт } \\
\text { миокарда }\end{array}$} & $\mathrm{M}$ & $1,8 \pm 0,08$ & $2,4 \pm 0,1$ & $6,1 \pm 0,3$ & $5,3 \pm 0,3$ & $2,97 \pm 079 * *$ \\
\hline & Ж & $1,2 \pm 0,03$ & $0,4 \pm 0,01$ & $3,8 \pm 0,1$ & $2,4 \pm 0,07$ & $0,87 \pm 0,31 * *$ \\
\hline \multirow[t]{2}{*}{ - стенокардия } & $\mathrm{M}$ & $5,4 \pm 0,2$ & $5,5 \pm 0,3$ & $8,4 \pm 0,4$ & $7,6 \pm 0,3$ & $6,57 \pm 1,18$ \\
\hline & Ж & $4,7 \pm 0,1$ & $3,4 \pm 0,09$ & $6,2 \pm 0,2$ & $5,7 \pm 0,2$ & $3,72 \pm 0,64 * *$ \\
\hline \multirow[t]{2}{*}{ - хроническая ИБС } & $\mathrm{M}$ & $64,8 \pm 2,6$ & $39,0 \pm 1,9$ & $71,2 \pm 3,4$ & $66,8 \pm 3,4$ & $58,71 \pm 3,42$ \\
\hline & Ж & $80,6 \pm 1,8$ & $43,0 \pm 1,1$ & $81,6 \pm 2,1$ & $69,4 \pm 1,8$ & $52,68 \pm 2,34 * * *$ \\
\hline
\end{tabular}

Примечание. Аналогично табл. 2. 
Значительный рост заболеваемости, как у мужчин, так и женщин зафиксирован в третьем периоде в обоих возрастных группах. На последнем этапе уровень заболеваемости остается высоким, однако отмечена тенденция к снижению.

Известно, что проявления заболевания ИБС наблюдаются уже до развития серьезного сердечно-сосудистого события, каким является инфаркт миокарда. Поэтому анализ данных о заболеваемости на стенокардию представляет определенный интерес (рис. 5).

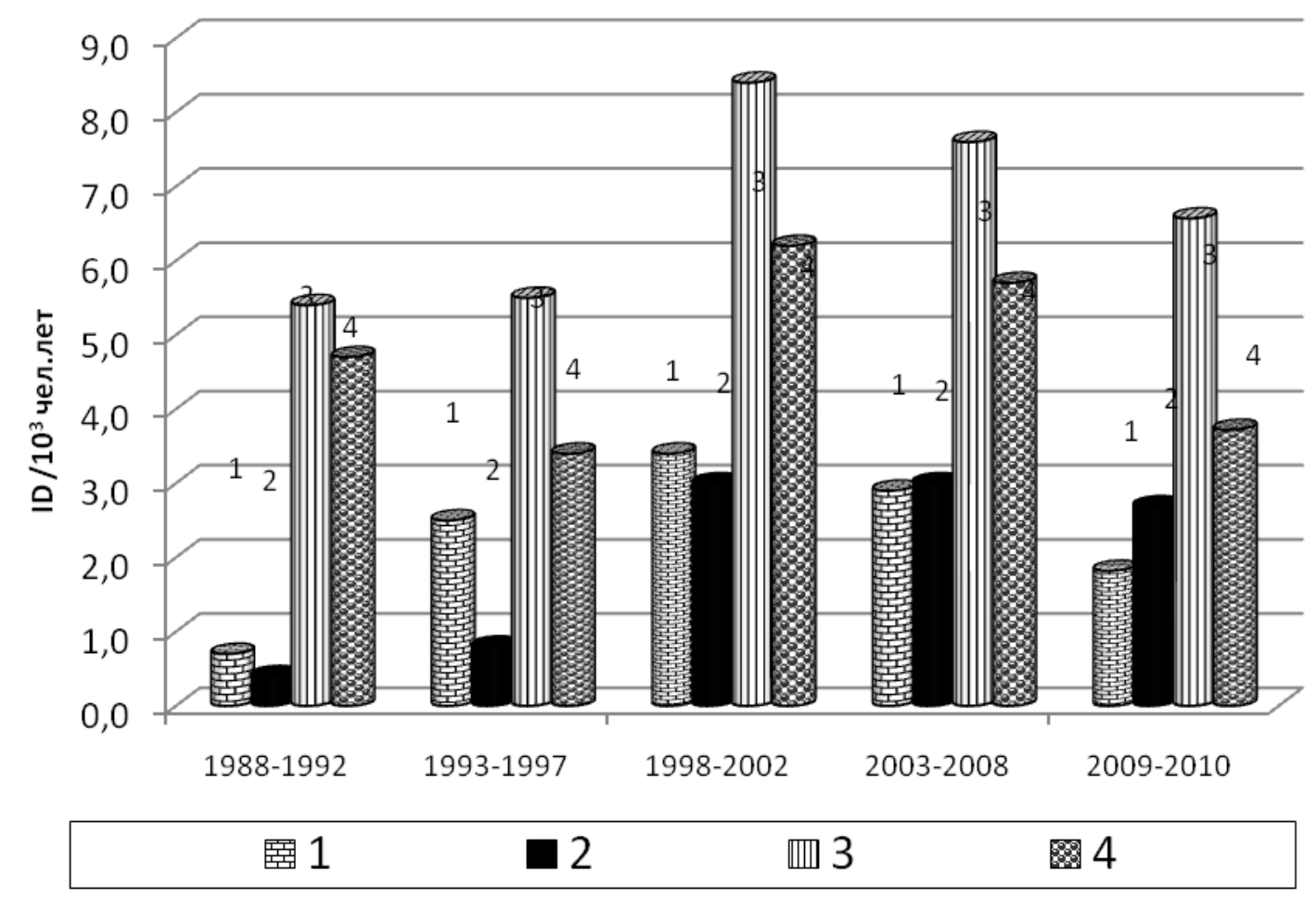

1 - заболеваемость мужчин в возрасте 18-39 лет стенокардией 2 - заболеваемость женщин в возрасте 18-39 лет стенокардией
3 - заболеваемость мужчин в возрасте 40-60 лет стенокардией

4 - заболеваемость женщин в возрасте 40-60 лет стенокардией

Рисунок 5. Динамика заболеваемости стенокардией взрослого на момент аварии эвакуированного населения в зависимости от возраста и пола по периодам наблюдения (ID / $10^{3}$ чел.-лет )

Как видно из рис. 5 у лиц эвакуированных в возрасте 18-39 лет отмечен более существенный рост частоты стенокардии в первые 10 лет после аварии. В обеих возрастных группах максимальные уровни отмечены на третьем этапе наблюдения с последующим снижением в периоде 2009-2010 гг.

Уровень заболеваемости стенокардией у мужчин в возрасте 18-39 лет выше, чем у женщин в третьем периоде, в четвертом периоде показатели почти одинаковые, а на последнем этапе уровень заболеваемости у женщин выше, чем у мужчин. В тоже время 
показатели заболеваемости у женщин и мужчин остаются выше по сравнению с первым периодом наблюдения.

В возрасте 40-60 лет наблюдается аналогичная картина. Однако, на последнем этапе наблюдения показатели заболеваемости у мужчин выше, чем у женщин. Уровень заболеваемости стенокардией сравнялся с показателем первого периода.

Наиболее тяжелым последствием ИБС является инфаркт миокарда. По данным авторов инфаркт миокарда [7] и его последствия в настоящее время, являются одной из основных причин инвалидизации и смертности пострадавших в результате аварии на ЧАЭС. Авторы отмечают, что спустя 11 лет с момента аварии частота инфаркта миокарда пострадавших возросла почти вдвое и в последующие годы прогнозируется дальнейший рост вследствие увеличения возраста.

Данные о заболеваемости взрослого эвакуированного населения инфарктом миокарда приведены на рис. 6.

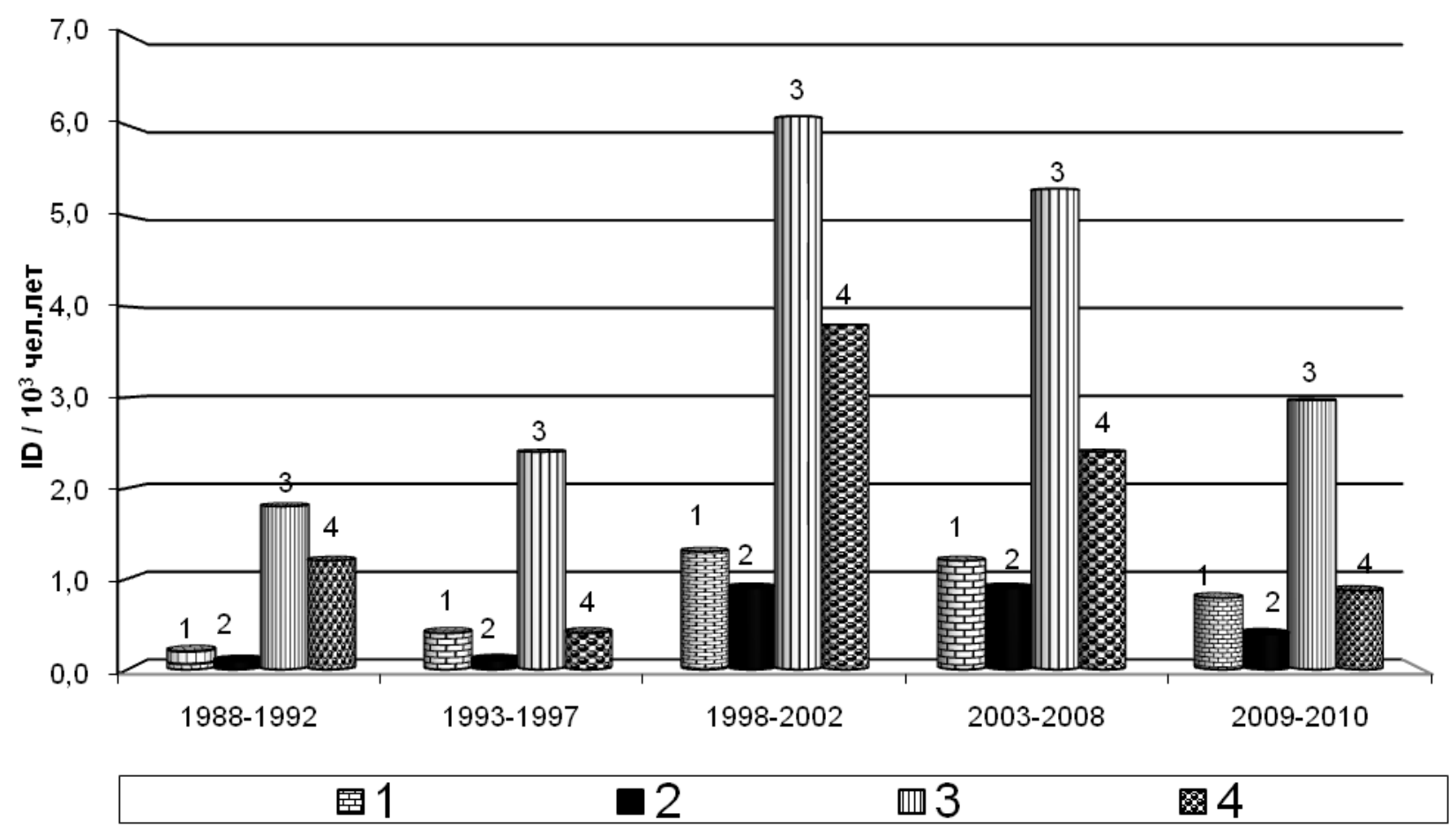

1 - заболеваемость мужчин в возрасте

3 - заболеваемость мужчин в возрасте

18-39 лет инфарктом миокарда

2 - заболеваемость женщин в возрасте

18-39 лет инфарктом миокарда

40-60 лет инфарктом миокарда

4 - заболеваемость женщин в возрасте

40-60 лет инфарктом миокарда

Рисунок 6. Динамика заболеваемости инфарктом миокарда в когорте взрослого эвакуированного населения в зависимости от пола и возраста по периодам наблюдения (ID / $10^{3}$ чел.-лет ) 
Как свидетельствуют данные (рис. 6) уровень заболеваемости инфарктом миокарда в обеих возрастных группах повышался до третьего периода наблюдения. В дальнейшем наблюдается снижение значения показателя, однако они остаются высокими по сравнению с первым и вторым периодами исследований. При этом частота инфаркта миокарда у лиц старше 40 лет выше, чем в лиц в возрасте 18-39 лет.

Такая же зависимость отмечена и по половому признаку. Показатели заболеваемости инфарктом миокарда у мужчин выше, чем у женщин в обеих возрастных группах. Как у мужчин, так и женщин показатели заболеваемости в последние годы выше, чем в первые годы после аварии, за исключением женщин в период 2009-2010 годов.

При сопоставлении заболеваемости ИБС взрослого эвакуированного населения с группой сравнения (взрослое население Украины) установлен более высокий процент заболеваемости среди эвакуированных по сравнению с взрослым населением Украины.

Эвакуированное взрослое население

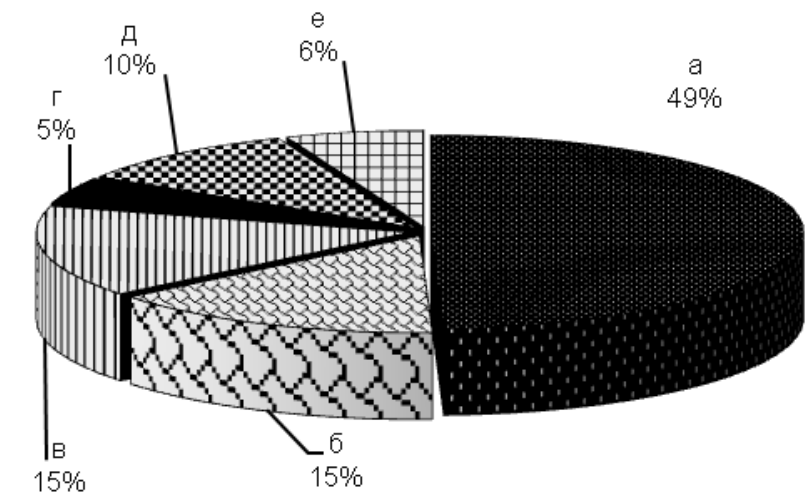

Взрослое население Украины

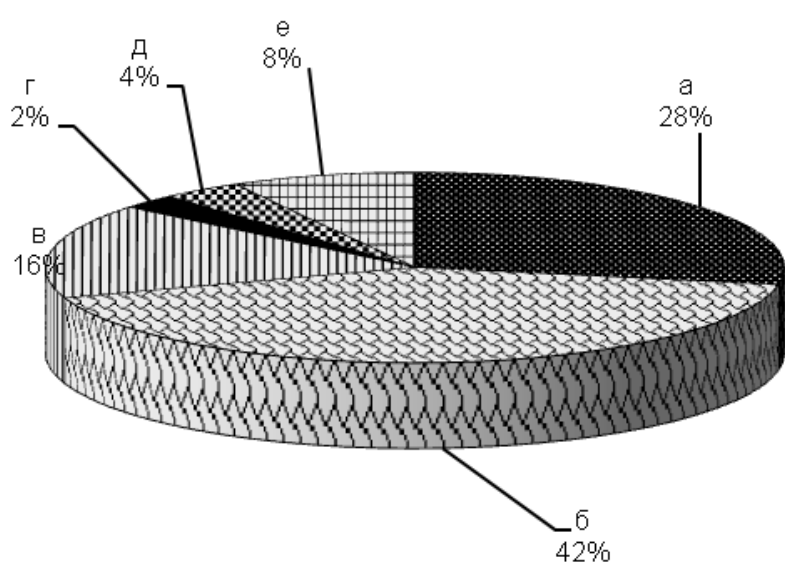

а- ИБС; б- ГБ ; в - ЦВБ; г- заболевания артерий; д - заболевания вен; е - другие заболевания

Рисунки 7 и 8. Удельный вес заболеваемости ИБС в структуре болезней системы кровообращения взрослого эвакуированного населения и взрослого населения Украины в 2010 году в \%.

Если, среди взрослого населения Украины удельный вес ИБС в структуре болезней системы кровообращения (БСК) составил 24,6\% в 1993 году, то среди эвакуированного взрослого населения он составил 30,3\%. В течение последних пяти лет (2006-2010 гг.) удельный вес ИБС среди взрослого населения Украины оставался на одном уровне (27,5 $28,2 \%)$, в то время как среди эвакуированных он постепенно возрастал и достиг 49,4\%. Наши данные совпадают с данными, полученными в отношении БСК у участников 
ликвидации последствий Чернобыльской аварии [7]. Показатели заболеваемости хронической ИБС на 11,5\% превысили этот показатель среди населения Украины.

Настоящие результаты позволяют высказать предположение о возможной связи роста частоты ИБС в исследуемом контингенте пострадавших с радиационным облучением и влиянием комплекса факторов нерадиационной природы, связанных и не связанных с последствиями аварии на ЧАЭС, что является задачей дальнейших аналитических эпидемиологических исследований.

\section{Выводы}

1. За результатами 24 летнего медицинского наблюдения установлено, что заболеваемость ИБС взрослого эвакуированного населения имеет существенные возрастные, половые и временные отличия.

2. Повышение уровня заболеваемости ИБС независимо от возраста на момент аварии следует отнести на период 12 - 22 года. Пик заболеваемости у лиц, возраст которых на момент аварии составил 40-60 лет, отмечен в третьем периоде наблюдения, т.е. спустя 12-16 лет с момента аварии на ЧАЭС, то у лиц, эвакуированных в возрасте 18-39 лет - спустя 17-22 года и сохраняется на таком же уровне в последнем периоде. Спустя 24 года после аварии заболеваемость эвакуированных в возрасте 18-39 лет превышает показатели первого периода в 4 раза, а второго периода - в 3 раза. В возрастной группе 40-60 лет в последний период наблюдения отмечено снижение уровня заболеваемости.

Обращает внимание достаточно высокий уровень заболеваемости ИБС лиц, возраст которых на момент аварии составил 40-60 лет в первые шесть лет с момента аварии, что, очевидно, обусловлено влиянием трех основных факторов: «возраст», «скрининг-эффект»и «психо-социальный стресс».

3. У лиц, эвакуированных в возрасте 18-39 лет не установлено достоверной разницы в уровне заболеваемости мужчин и женщин, в то время, как у женщин, 40-60 лет показатели заболеваемости ИБС выше по сравнению с мужчинами, за исключением последнего этапа наблюдения.

4. В отношении форм ИБС можно отметить превалирование хронической ИБС. У лиц, эвакуированных в возрасте 18-39 лет, отмечен более высокий темп роста частоты стенокардии и инфаркта миокарда в сравнении с возрастной группой 40-60 лет. В 2009-2010 гг. уровень заболеваемости этими болезнями у лиц, эвакуированных в возрасте 4060 лет, почти сравнялся с заболеваемостью начальных этапов наблюдения. 


\section{References}

\section{Литература}

1. Лутай М.И. Медикаментозное лечение ИБС: доказанная эффективность, нерешенные проблемы / М.И.Лутай // Здоров’я України. - 2003. - № 23-24. - С.12).

2. Проблеми радіаційної медицини та безпеки України в XX1 столітті: історичне минуле та сучасні завдання / А.М. Сердюк, Д.А.Базика, І.П. Лось, А.С. Присяжнюк, В.В.Чумак - Науковий журнал МОЗ України, 2013. - № 1. C. 7-17).

3.Гіпертонічна хвороба / I.М.Хомазюк, Ж.М.Габулавічене, О.М. Настіна (та ін.) // Медичні наслідки Чорнобильської катастрофи: 1986-2011 /за ред.. А.М.Сердюка, В.Г.Бебешка, Д.А.Базики. - Тернопіль: ТДМУ; Укрмедкнига, 2011. - С.412-436.

4. Пирогова О.Я. Серцево-судинна захворюваність евакуйованого з 30-км зони ЧАЕС населення в після евакуаційному періоді (епідеміологічне дослідження) / О.Я.Пирогова, В.О.Бузунов, Т.Є.Домашевська. - Пробл. рад. мед. та радіобіол., 2011. - Вип. 16. - С.50-58.

5. Пирогова О.Я. Непухлинна захворюваність дорослого населення, евакуйованого 3 30-км зони ЧАЕС: дінамика, вплив малих доз іонізуючого випромінювання (епідеміологічні дослідження) / О.Я. Пирогова, В.О Бузунов, В.А Цуприков, Т.С Домашевська. - Пробл. рад. мед. та радіобіол., 2010. - вип.15. - С.100 - 114.

6. Настіна О.М. Радіаційні та нерадіаційні фактори ризику в розвитку хронічної ішемічної хвороби серця в учасників ліквідації наслідків Чорнобильської катастрофи у віддалений період. / Пробл. рад. мед. та радіобіол., 2010. - вип.15. - С.145 - 152.

7. Хомазюк I.M. Особливості хронічної ішемічної хвороби серця в учасників ліквідації наслідків Чорнобильської аварії, які перенесли інфаркт міокарда / І.М.Хомазюк, Ж.М.Габулавічене, О.М. Настіна (та ін..)// Медичні наслідки Чорнобильської катастрофи: 1986-2011 /за ред.. А.М.Сердюка, В.Г. Бебешка, Д.А.Базики. - Тернопіль: ТДМУ; Укрмедкнига, 2011. - С. 436-445. 